\title{
Association of TCF7L2 Gene Polymorphisms with T2DM in the Population of Juana Koslay, San Luis Province, Argentina
}

\author{
Susana Siewert, Federico Márquez, Gisela Mendoza, Gustavo Fernández, Irma González, \\ Marta S. Ojeda \\ Laboratory of Diabetes, Department of Biochemistry and Biological Sciences, School of Chemistry, \\ Biochemistry and Pharmacy, National University of San Luis, San Luis, Argentina \\ Email: msojeda@unsl.edu.ar
}

Received 27 February 2015; accepted 14 March 2015; published 18 March 2015

Copyright (C) 2015 by authors and OALib.

This work is licensed under the Creative Commons Attribution International License (CC BY).

http://creativecommons.org/licenses/by/4.0/

(c) (i) Open Access

\section{Abstract}

Polymorphisms in the gene coding for transcription factor 7 like 2 (TCF7L2) are recognized as the strongest common genetic risk factors for Type 2 Diabetes Mellitus (T2DM) across multiple ethnicities. This study was conducted to evaluate an association between TCF7L2 variants and diabetes susceptibility in the population of Juana Koslay, San Luis, Argentina. We genotyped 2 single nucleotide polymorphisms (SNP) rs7903146 and rs12255372 in controls and diabetic subjects. Association with T2DM was found for both SNPs rs7903146 and rs12255372 in the whole sample (under a dominant genetic model, the odds ratios (OR) were $3.43,95 \%$ CI [1.879 - 6.255], p < 0.0001 and $\mathrm{OR}=4.40,95 \% \mathrm{CI}[2.318-8.351], \mathrm{p}<0.0001$, respectively). The risk conferred by homozygotes is much higher than the heterozygote carriers and it is marked in case of rs7903146. The haplotype that consisted of two minor alleles (TT) or the haplotypes carrying at least one of the minor alleles at SNP rs7903146 or rs12255372 (i.e. CT or TG) were more frequent in the group of T2DM. The impact of TCF7L2 variation on T2DM risk in Juana Koslay population is compatible with that demonstrated by a range of studies conducted in various ethnic groups.

\section{Keywords}

Haplotypes, Alleles, Homozygotes, TCF7L2, Polymorphisms, Type 2 Diabetes Mellitus

Subject Areas: Diabetes \& Endocrinology

\section{Introduction}

Type 2 diabetes mellitus (T2DM) represents the most common major form of diabetes, which results from a

How to cite this paper: Siewert, S., Márquez, F., Mendoza, G., Fernández, G., González, I. and Ojeda, M.S. (2015) Association of TCF7L2 Gene Polymorphisms with T2DM in the Population of Juana Koslay, San Luis Province, Argentina. Open Access Library Journal, 2: e1419. http://dx.doi.org/10.4236/oalib.1101419 
defect in insulin secretion, almost always with a major contribution from insulin resistance. The incidence and prevalence of T2DM have reached epidemic proportions all over the world. It is predicted that there will be at least 350 million people in the world with T2DM by the year 2030, unless appropriate action is taken [1].

The highest incidence of T2DM is seen in developing countries where $80 \%$ of deaths occur due to diabetes [2]. The increased prevalence of type 2 diabetes is thought to be due to environmental factors, acting on genetically susceptible individuals. The heritability of T2DM is one of the best established among common diseases [3] [4], and consequently, genetic risk factors for T2DM have been the subject of intense research [5]. Recently, research on genetic factors in T2DM has become more and more frequent and there is no doubt that the transcription factor 7-like 2 (TCF7L2) emerges as one of the strongest T2DM susceptibility genes among the possible candidate genes.

The most significant genetic T2DM association within TCF7L2 was detected for two intronic single nucleotide polymorphisms (SNPs), rs7903146 and rs12255372, located $50 \mathrm{~kb}$ from each other within a $92 \mathrm{~kb}$ linkage disequilibrium (LD) block spanning exon 4 and parts of introns 3 and 4 [6]-[20]. All exons of TCF7L2 were sequenced in multiple patients and controls but no coding variation was identified [6] suggesting that T2DM risk is associated with a non-coding variation. Genetic variations may affect levels of expression and splicing architecture of mRNA transcripts [21] [22] thus several studies have tested the relationships between TCF7L2 mRNA expression and genotypes of rs7903146 and rs12255372 in human tissues [23] [24].

The Argentina population is genetically heterogeneous. Aside from the native indigenous population, nearly all Argentinean or their ancestors immigrated within the past five centuries. Therefore, most Argentinean are of European descent, and are either descendents of colonial-era settlers and/or of the 19th and 20th century immigrants from Europe. Therefore over 90\% of the population is of ethnic European descent. Variants of TCF7L2 gene have not previously been investigated in any population from Argentina.

Here, we aimed to investigate rs7903146 and rs12255372 polymorphisms in TCF7L2 in a case-control study of a well known Argentinean population, who reside in Juana Koslay-San Luis Province, to confirm the association of these 2 polymorphisms in TCF7L2 and T2DM. This population is particular because of its ethnic background, mainly Native-South American Hispanic.

\section{Research Design and Methods}

\subsection{Subjects}

The present study was carried out in accordance with the guidelines of the Helsinki Declaration. A total of 196 volunteers (108 patients with type 2 diabetes and 88 healthy age-matched controls) participated in this investigation. Criteria published by the American Diabetes Association were used to diagnose T2DM [25]. These patients reside in Juana Koslay, San Luis, Argentina. The protocol for this study was approved by the local Institutional Review Board, and a written informed consent was obtained from each patient to be enrolled. During an initial interview with each patient, they were asked for diseases, medication and smoking histories. Exclusion criteria included liver, kidney and thyroid diseases, as well as the use of anti-lipemic drugs.

\subsection{Anthropometric and Clinical Data}

For each subject enrolled, height (meters) and weight (kg) measurements were acquired. Height and weight were measured to the nearest $0.5 \mathrm{~cm}$ and $0.1 \mathrm{~kg}$, respectively. The body mass index (BMI) was calculated as weight divided by height squared $\left(\mathrm{kg} / \mathrm{m}^{2}\right)$.

\subsection{Blood Sampling}

Venous blood samples for glucose, lipid, and lipoprotein analysis were collected into EDTA-containing (1 g/liter) tubes from all subjects after a 12-h overnight fast at the beginning of the study. Blood was also collected to extract DNA (see below).

\subsection{Biochemical Measurement}

Fasting plasma glucose (FPG) was measured by using a glucose oxidase method with a commercial enzymatic kit (Wiener Lab, Rosario, Argentina) and Glycated hemoglobin (HbA1c) concentration was measured with a 
coupled ionic-exchange chromatography/spectrophotometric assay (BioSystems, Barcelona, Spain) in a Bayer Express Plus Chemistry Analyzer (Bayer Diagnostics, Siemens, Germany). Total cholesterol (TC), triglycerides (TG) and HDL-c concentrations were measured using commercial kits by following manufacturer's instructions ((Wiener Lab, Rosario, Argentina) in a Bayer Express Plus Chemistry Analyzer (Bayer Diagnostics, Siemens, Germany). Low density lipoprotein-cholesterol (LDL-c) was calculated with the Friedewald formula: LDL-c = total cholesterol (mg/dL) - HDL-c (mg/dL) - triglycerides (mg/dL)/5 [26].

\subsection{Genotyping and SNPs Analysis}

Genomic DNA was isolated from diabetic patients and healthy volunteers using conventional protocol by Qiagen kits (Qiagen, Inc., Valencia, CA). DNA concentration was detected by UV-VIS spectroscopy and diluted to a final concentration of $20 \mathrm{ng} / \mu \mathrm{L}$. The TCF7L2 polymorphisms rs12255372 (G/T) and rs7903146 (C/T) were analyzed by Tetra Primer AMRS-PCR [27]. Nucleotide sequence and SNP details were obtained from NCBI website (www.ncbi.nih.gov/nucoore/KJ892257.1). The primers were designed "in silico" in a free access web (http://cedar.genetics.soton.ac.uk) and then checked for specificity (http://blast.ncbi.nlm.nih.gov/Blast.cgi). Each PCR reaction was carried out in a total volume of $35 \mu \mathrm{L}$, containing $200 \mathrm{ng}$ of template DNA, 10 pmol of each inner primer, 1 pmol of each outer primer (Table 1), $200 \mu \mathrm{M}$ dNTPs, $2.5 \mathrm{mM} \mathrm{MgCl} 2$, $1 \mathrm{X}$ buffer, and 1 unit of AmpliTaq Gold DNA polymerase (Perkin-Elmer). The template DNA was denatured for 3 minutes at $95^{\circ} \mathrm{C}$ before undergoing 35 cycles of denaturation for 1 minute at $95^{\circ} \mathrm{C}$, primer annealing for 1 minute (annealing temperatures for different PCRs are described in Table 1), and extension for 1 minute at $72^{\circ} \mathrm{C}$, and final extension at $72^{\circ} \mathrm{C}$ for 3 minutes. The resultant products obtained after PCR were separated by electrophoresis on $2.5 \%$ agarose gel containing GelRed. The image was visualized and photographed under UV transillumination. Allele frequencies for SNPs were calculated by allele counting. Randomly selected $20 \%$ of samples were re-genotyped for cross validating initial genotypes. In case of unclear genotyping results, the samples were repeated again in duplicates till clear genotype was available. Unclear genotyping results, even after repetition was excluded from the study. No genotyping error was observed during cross validation.

\subsection{Statistical Analysis}

Chi square test was used to check adjustment of the data to the Hardy-Weinberg equilibrium and to compare the allelic frequencies between controls and diabetic subjects. Comparison of allele frequencies and genotype distributions between case and control samples were done by Pearson's chi- square test. To analyze the association between TCF7L2 genotypes, clinical and biochemical parameters a Student $t$-test was used when variables were continuous, whereas a Fisher's exact test was used for the categorical variables. Tests for association of each SNP or haplotype with T2DM were performed by using the Haploview software. A p $<0.05$ was considered to be statically significant.

Table 1. PCR primers and conditions.

\begin{tabular}{|c|c|c|c|}
\hline $\begin{array}{l}\text { Genetic } \\
\text { polymorphism }\end{array}$ & Primer sequence & $\begin{array}{l}\text { Annealing } \\
\text { temperature }\end{array}$ & Amplicon size \\
\hline \multirow{4}{*}{ rs12255372 (G/T) } & $\begin{array}{l}\text { Forward inner primer (T allele) } \\
\text { 5'CTGCCCAGGAATATCCAGGCAAGAGTT 3' }\end{array}$ & $58^{\circ} \mathrm{C}$ & 362 bp (T allele) \\
\hline & $\begin{array}{l}\text { Reverse inner primer (G allele) } \\
\text { 5’GAGGCCTGAGTAATTATCAGAATATGATC 3' }\end{array}$ & & 281 bp (G allele) \\
\hline & $\begin{array}{l}\text { Forward outer primer } \\
\text { 5’ GGCTGTATGAAGTCATTTGATGATTGTTT 3' }\end{array}$ & & \multirow[t]{2}{*}{587 bp (from two outer primers) } \\
\hline & $\begin{array}{l}\text { Reverse outer primer } \\
\text { 5’ACGCTTTGAAGGTAGAGAGGACACACT 3’ }\end{array}$ & & \\
\hline \multirow{4}{*}{ rs7903146 (C/T) } & $\begin{array}{l}\text { Forward inner primer (C allele) } \\
\text { 5’CAATTAGAGAGCTAAGCACTTTTTAGAGAC 3' }\end{array}$ & \multirow[t]{4}{*}{$58^{\circ} \mathrm{C}$} & 306 bp (C allele) \\
\hline & $\begin{array}{l}\text { Reverse inner primer (T allele) } \\
\text { 5’TGCCTCATACGGCAATTAAATTATAGAA 3' }\end{array}$ & & 172 bp (T allele) \\
\hline & $\begin{array}{l}\text { Forward outer primer } \\
\text { 5’GTAATGCAGATGTGATGAGATCTCTG 3' }\end{array}$ & & \multirow[t]{2}{*}{420 bp (from two outer primers) } \\
\hline & $\begin{array}{l}\text { Reverse outer primer } \\
\text { 5'AGAAAAATACAAAGACATGCAAAAGC 3, }\end{array}$ & & \\
\hline
\end{tabular}




\section{Results}

\subsection{Subject Characteristics}

The anthropometric and clinical characteristics of the subjects in our study are shown in Table 2.

\subsection{Association Results}

Both polymorphisms were found to be in Hardy Weinberg Equilibrium. In agreement with previous studies, the minor allele of each SNP was significantly associated with type 2 diabetes (Table 3). The strongest association was seen for the variant rs7903146, with an allelic OR of $4.17(2.639-6.580, \mathrm{p}<0.0001)$.

\subsection{Inheritance Model of TCF7L2 SNPs}

For both SNPs, the association was consistent with a dominant model of inheritance (Table 4 and Table 5).

\subsection{Association of TCF7L2 Variants with Clinical and Biochemical Subject Characteristics}

Table 6 shows anthropometric and clinical characteristics by the TCF7L2 polymorphism rs7903146 in controls and T2DM. Because of the small number of subjects, homozygotes for the minor allele $\mathrm{T}$ and heterozygotes

Table 2. Anthropometric and clinical characteristics of subjects studied.

\begin{tabular}{cccc}
\hline & Control subjects $(\mathbf{n}=\mathbf{8 8})$ & T2DM subjects $(\mathbf{n}=\mathbf{1 0 8})$ & p \\
\hline Age (years) & $55.45 \pm 12.16$ & $59.12 \pm 8.41$ & 0.1808 \\
Weight (kg) & $71.33 \pm 16.92$ & $89.18 \pm 13.73$ & 0.0003 \\
Height (m) & $1.66 \pm 0.08$ & $1.75 \pm 0.08$ & 0.0009 \\
BMI (kg/m $)$ & $24.29 \pm 3.28$ & $30.82 \pm 4.02$ & $<0.0001$ \\
FPG (mg/dL) & $87.50 \pm 14.05$ & $180.59 \pm 84.49$ & $<0.0001$ \\
HbA1c (\%) & $5.41 \pm 0.66$ & $8.78 \pm 2.95$ & $<0.0001$ \\
TC (mg/dL) & $166.79 \pm 22.74$ & $199.20 \pm 38.20$ & 0.0037 \\
HDL-c (mg/dL) & $42.00 \pm 6.54$ & $36.50 \pm 5.28$ & 0.0057 \\
LDL-c (mg/dL) & $111.63 \pm 27.38$ & $139.50 \pm 24.72$ & 0.0038 \\
TG (mg/dL) & $121.70 \pm 31.09$ & $229.00 \pm 114.28$ & $<0.0001$ \\
\hline
\end{tabular}

Data are shown as mean \pm SD.

Table 3. Association of TCF7L2 variants with type 2 diabetes mellitus.

\begin{tabular}{|c|c|c|c|c|c|c|c|c|c|}
\hline SNP & Allele & $\begin{array}{c}\text { Control } \\
\text { Subjects } \\
\mathbf{F}^{\mathbf{a}}\end{array}$ & $\begin{array}{c}\text { T2DM } \\
\text { Subjects } \\
\mathbf{F}^{\mathbf{a}}\end{array}$ & Genotype & $\begin{array}{c}\text { Control } \\
\text { subjects } \\
\text { n (\%) }\end{array}$ & $\begin{array}{c}\text { T2DM } \\
\text { subjects } \\
\text { n (\%) }\end{array}$ & $\begin{array}{c}\text { Allelic OR } \\
(95 \% \text { CI) }\end{array}$ & $\begin{array}{c}\text { Het OR }{ }^{d} \\
(95 \% \text { CI })\end{array}$ & $\begin{array}{c}\text { Hom OR } \\
(95 \% \text { CI })\end{array}$ \\
\hline \multirow{3}{*}{ rs7903146 } & $\mathrm{C}$ & 0.75 & 0.54 & $\mathrm{CC}$ & $48(54.5)$ & 28 (25.9) & 4.17 & 2.86 & 8.57 \\
\hline & & & & CT & $36(41.0)$ & $60(55.6)$ & $(2.639-6.580)$ & $(1.532-5.327)$ & $(2.659-27.634)$ \\
\hline & $\mathrm{T}$ & 0.25 & 0.46 & $\mathrm{TT}$ & $4(4.5)$ & 20 (18.5) & $\mathrm{p}<0.0001$ & $\mathrm{p}=0.0012$ & $\mathrm{p}<0.0001$ \\
\hline \multirow{3}{*}{ rs12255372 } & G & 0.73 & 0.54 & GG & $44(50.0)$ & 20 (18.5) & 2.29 & 4.18 & 6.60 \\
\hline & & & & $\mathrm{GT}$ & $40(45.4)$ & $76(70.4)$ & $(1.501-3.521)$ & $(2.176-8.030)$ & $(1.892-23.019)$ \\
\hline & $\mathrm{T}$ & 0.27 & 0.46 & $\mathrm{TT}$ & $4(4.5)$ & $12(11.1)$ & $\mathrm{p}<0.0001$ & $\mathrm{p}<0.0001$ & $p=0.0033$ \\
\hline
\end{tabular}

${ }^{\mathrm{a}} \mathrm{F}=$ Allele frequency. ${ }^{\mathrm{b}}$ Genotype frequency expressed as number of individuals, $\mathrm{n}$ —values in parentheses indicate percentage. ${ }^{\mathrm{c}} \mathrm{OR}=$ odds ratio, $95 \%$ $\mathrm{CI}=95 \%$ confidence interval. ${ }^{\mathrm{d}}$ Genotype odds ratios calculated compared with homozygotes for common allele; Het OR = odds ratio for heterozygous genotype, Hom OR = odds ratio for minor allele homozygous genotype. 
Table 4. Risk analysis of the variant rs7903146 according to the model of inheritance.

\begin{tabular}{|c|c|c|c|c|c|}
\hline Model $^{\mathbf{a}}$ & Genotype $^{b}$ & Control subjects n (\%) & T2DM subjects n (\%) & $\mathbf{p}$ & $\mathrm{OR}^{\mathrm{c}}(95 \% \mathrm{CI})$ \\
\hline \multirow{3}{*}{ Co } & $\mathrm{CC}$ & $48(54.5)$ & 28 (25.9) & & 1 \\
\hline & $\mathrm{CT}$ & $36(41.0)$ & $60(55.6)$ & $<0.0001$ & $2.86(1.532-5.327)$ \\
\hline & $\mathrm{TT}$ & $4(4.5)$ & $20(18.5)$ & & $8.57(2.659$ - 27.634) \\
\hline \multirow{2}{*}{ Do } & $\mathrm{CC}$ & $48(54.5)$ & 28 (25.9) & $<0.0001$ & 1 \\
\hline & $\mathrm{CT}-\mathrm{TT}$ & $40(45.5)$ & $80(74.1)$ & & $3.43(1.879-6.255)$ \\
\hline \multirow{2}{*}{$\operatorname{Re}$} & CC-CT & $84(95.5)$ & $88(81.5)$ & 0.0037 & 1 \\
\hline & $\mathrm{TT}$ & $4(4.5)$ & $20(18.5)$ & & $4.77(1.566-14.550)$ \\
\hline \multirow{2}{*}{ Od } & CC-TT & $52(59.0)$ & $48(44.4)$ & 0.045 & 1 \\
\hline & $\mathrm{CT}$ & $36(41.0)$ & $60(55.6)$ & & $1.81(1.021-3.192)$ \\
\hline
\end{tabular}

${ }^{\mathrm{a}}$ Inherintance models: codominant (Co), dominant (Do), recessive (Re), overdominant (Od). ${ }^{\mathrm{b}}$ Genotypes and their groupings for the variant rs7903146 $(\mathrm{C}>\mathrm{T}) .{ }^{\mathrm{C}} \mathrm{OR}=$ odds ratio, $95 \% \mathrm{CI}=95 \%$ confidence interval.

Table 5. Risk analysis of the variant rs12255372 according to the model of inheritance.

\begin{tabular}{|c|c|c|c|c|c|}
\hline Model $^{\mathrm{a}}$ & Genotype $^{b}$ & Control subjects n (\%) & T2DM subjects n (\%) & $\mathbf{p}$ & $\mathrm{OR}^{\mathrm{c}}(95 \% \mathrm{CI})$ \\
\hline \multirow{3}{*}{ Co } & GG & $44(50.0)$ & 20 (18.5) & & 1 \\
\hline & GT & $40(45.5)$ & $76(70.4)$ & $<0.0001$ & $4.18(2.176-8.030)$ \\
\hline & $\mathrm{TT}$ & $4(4.5)$ & $12(11.1)$ & & $6.60(1.892-23.019)$ \\
\hline \multirow{2}{*}{ Do } & GG & $44(50.0)$ & $20(18.5)$ & $<0.0001$ & 1 \\
\hline & GT-TT & $44(50.0)$ & $88(81.5)$ & & $4.40(2.318-8.351)$ \\
\hline \multirow{2}{*}{$\mathrm{Re}$} & GG-GT & $84(95.5)$ & 86 (88.9) & 0.07 & 1 \\
\hline & TT & $4(4.5)$ & $12(11.1)$ & & $2.93(0.908-9.452)$ \\
\hline \multirow{2}{*}{ Od } & GG-TT & $48(54.5)$ & $32(29.6)$ & 0.0005 & 1 \\
\hline & GT & $40(45.5)$ & $76(70.4)$ & & $2.85(1.582-5.136)$ \\
\hline
\end{tabular}

${ }^{\mathrm{a}}$ Inherintance models: codominant (Co), dominant (Do), recessive (Re), overdominant (Od). ${ }^{\mathrm{b}}$ Genotypes and their groupings for the variant rs12255372 (G > T). ${ }^{\mathrm{C}} \mathrm{OR}=$ odds ratio, $95 \% \mathrm{CI}=95 \%$ confidence interval.

Table 6. Anthropometric and clinical characteristics by the TCF7L2 polymorphism rs7903146 in controls and T2DM.

\begin{tabular}{|c|c|c|c|c|c|c|}
\hline & \multicolumn{2}{|c|}{ Control subjects $(\mathrm{n}=\mathbf{8 8})$} & \multirow{2}{*}{$\mathbf{p}$} & \multicolumn{2}{|c|}{ T2DM subjects $(\mathrm{n}=108)$} & \multirow{2}{*}{$\mathbf{p}$} \\
\hline & CC & CT-TT & & CC & CT-TT & \\
\hline BMI (kg/m²) & $22.79 \pm 2.71$ & $25.46 \pm 3.33$ & 0.0907 & $32.66 \pm 3.37$ & $30.25 \pm 4.15$ & 0.1630 \\
\hline FPG (mg/dL) & $89.09 \pm 15.83$ & $85.56 \pm 12.16$ & 0.6201 & $154.50 \pm 38.18$ & $190.38 \pm 95.56$ & 0.7399 \\
\hline HbA1c (\%) & $5.22 \pm 0.60$ & $5.66 \pm 0.69$ & 0.1642 & $9.32 \pm 2.47$ & $8.61 \pm 3.14$ & 0.3634 \\
\hline TC (mg/dL) & $158.50 \pm 22.27$ & $176.00 \pm 20.61$ & 0.0674 & $215.00 \pm 28.39$ & $193.71 \pm 40.68$ & 0.1195 \\
\hline HDL-c (mg/dL) & $44.91 \pm 7.62$ & $38.80 \pm 2.97$ & 0.0138 & $38.00 \pm 4.86$ & $35.86 \pm 5.49$ & 0.2131 \\
\hline LDL-c (mg/dL) & $106.10 \pm 27.47$ & $117.78 \pm 27.53$ & 0.3135 & $136.14 \pm 18.88$ & $141.31 \pm 27.91$ & 0.7813 \\
\hline TG (mg/dL) & $120.90 \pm 28.09$ & $122.50 \pm 35.35$ & 0.9097 & $236.00 \pm 71.05$ & $226.00 \pm 130.82$ & 0.3634 \\
\hline
\end{tabular}

Data are shown as mean \pm SD. Abbreviations used: BMI, body mass index; FPG, fasting plasma glucose; HbA1c, glycated hemoglobin; TC, total cholesterol; HDL, high density lipoprotein; LDL, low density lipoprotein; TG, triglycerides. 
were grouped as carriers of the T allele (CT and TT). In diabetic patients, no differences in anthropometric and clinical characteristics were detected in carriers of the allele T of the TCF7L2 polymorphism rs7903146, whereas in controls the presence of the allele $\mathrm{T}$ was associated with an decrease in HDL-c and slight increase in BMI and total cholesterol as compared with the CC homocygotes.

Table 7 shows anthropometric and clinical characteristics by the TCF7L2 polymorphism rs12255372 in controls and T2DM. Because of the small number of subjects, homozygotes for the minor allele $\mathrm{T}$ and heterozygotes were grouped as carriers of the T allele (GT and TT). In diabetic patients, no differences in anthropometric and clinical characteristics were detected in carriers of the allele T of the TCF7L2 polymorphism rs12255372, whereas in controls the presence of the allele $\mathrm{T}$ was associated with an increase in BMI and slight decrease in HDL-c as compared with the GG homocygotes.

\subsection{Association of TCF7L2 Haplotypes with T2DM}

The two SNPs (rs7903146 and rs12255372) defined four haplotypes. Estimated frequencies of the four common haplotypes with respect to the presence of T2DM are shown in Table 8. The haplotype that consisted of two minor alleles (TT) or the haplotypes carrying at least one of the minor alleles at SNP rs7903146 or rs12255372 (i.e. CT or TG) were more frequent in the group of T2DM. Conversely, the haplotypes that consisted of two common alleles at SNP rs7903146 and rs12255372 (GC) were more frequent in the control subjects than in T2DM subjects.

\section{Discussion}

TCF7L2 gene which spans about $215.9 \mathrm{~Kb}$ with 17 exons is a high mobility group box containing transcription factor involved in the WNT signaling pathway, playing a key role in cell development and regulatory mechanisms.

Table 7. Anthropometric and clinical characteristics by the TCF7L2 polymorphism rs12255372 in controls and T2DM.

\begin{tabular}{|c|c|c|c|c|c|c|}
\hline & \multicolumn{2}{|c|}{ Control subjects $(\mathrm{n}=\mathbf{8 8})$} & \multirow{2}{*}{$\mathbf{p}$} & \multicolumn{2}{|c|}{ T2DM subjects $(\mathrm{n}=108)$} & \multirow{2}{*}{$\mathbf{p}$} \\
\hline & GG & GT-TT & & GG & GT-TT & \\
\hline BMI $\left(\mathrm{kg} / \mathrm{m}^{2}\right)$ & $22.15 \pm 2.33$ & $25.57 \pm 3.16$ & 0.0268 & $29.05 \pm 0.91$ & $31.36 \pm 4.47$ & 0.6235 \\
\hline FPG (mg/dL) & $90.40 \pm 16.04$ & $84.60 \pm 11.85$ & 0.3625 & $169.25 \pm 77.10$ & $183.11 \pm 87.93$ & 0.7656 \\
\hline HbA1c (\%) & $5.29 \pm 0.61$ & $5.54 \pm 0.72$ & 0.3960 & $7.28 \pm 2.06$ & $9.13 \pm 3.06$ & 0.2263 \\
\hline TC (mg/dL) & $163.80 \pm 24.62$ & $170.11 \pm 21.42$ & 0.4592 & $193.20 \pm 44.89$ & $201.68 \pm 37.43$ & 0.6186 \\
\hline HDL-c (mg/dL) & $44.55 \pm 7.81$ & $39.20 \pm 3.26$ & 0.0744 & $38.00 \pm 4.69$ & $36.13 \pm 5.49$ & 0.2538 \\
\hline LDL-c (mg/dL) & $110.80 \pm 25.09$ & $112.56 \pm 31.26$ & 0.8415 & $132.50 \pm 31.27$ & $141.25 \pm 23.71$ & 0.5703 \\
\hline TG (mg/dL) & $122.00 \pm 29.25$ & $121.40 \pm 34.42$ & 0.9698 & $196.75 \pm 82.68$ & $237.06 \pm 121.77$ & 0.2012 \\
\hline
\end{tabular}

Data are shown as mean \pm SD. Abbreviations used: BMI, body mass index; FPG, fasting plasma glucose; HbA1c, glycated hemoglobin; TC, total cholesterol; HDL, high density lipoprotein; LDL, low density lipoprotein; TG, triglycerides.

Table 8. Estimated frequency of common haplotypes and their associations with T2DM.

\begin{tabular}{|c|c|c|c|c|c|}
\hline \multicolumn{2}{|c|}{ Haplotype } & \multirow{2}{*}{ Control subjects $\mathbf{F}^{\mathrm{a}}$} & \multirow{2}{*}{ T2DM subjects $\mathbf{F}^{\mathrm{a}}$} & \multirow{2}{*}{ OR $(95 \% \mathrm{CI})^{\mathrm{b}}$} & \multirow{2}{*}{$\mathbf{p}$} \\
\hline rs7903146 C > T & rs12255372 G > T & & & & \\
\hline $\mathrm{C}$ & G & 0.7954 & 0.1852 & 1 & - \\
\hline $\mathrm{C}$ & $\mathrm{T}$ & 0.0833 & 0.3518 & $22.17(10.973-44.778)$ & $<0.0001$ \\
\hline $\mathrm{T}$ & G & 0.0909 & 0.3518 & $16.22(8.734$ - 31.645) & $<0.0001$ \\
\hline $\mathrm{T}$ & $\mathrm{T}$ & 0.0454 & 0.1111 & $10.50(4.381-25.166)$ & $<0.0001$ \\
\hline
\end{tabular}

${ }^{\mathrm{a}} \mathrm{F}=$ Haplotype frequency. ${ }^{\mathrm{b}} \mathrm{OR}=$ odds ratio, 95\% CI = 95\% confidence interval were calculated by chi-squared tests by comparing each haplotype to the more common haplotype. 
WNT activity is important for lipid and glucose metabolism, pancreatic beta cell proliferation and function and for production of incretin hormone GLP-1 [28]. WNT signaling is also critical for glucagon like peptide-1 (GLP-1) secretion by the intestinal endocrine L-cells [29]. Thus, alteration in this pathway could lead to reduced secretion of GLP-1 which, in turn, could have effect on insulin secretion. The GLP-1, in concert with insulin, plays a critical role in blood glucose homeostasis. It has been postulated that TCF7L2 gene variants may confer susceptibility to T2DM indirectly by altering GLP-1 levels [30].

After a common microsatellite in the TCF7L2 gene region (DG10S478) was found to be associated with T2DM and this finding was convincingly replicated by Grant in 2006 [6] by using non-coding SNPs rs7903146, rs12255372, and rs11196205 that were in strong linkage disequilibrium with DG10S478, many other epidemiological study groups have detected a consistent association between these SNPs and T2DM.

Among the TCF7L2 SNPs investigated, four are well-studied, and included rs7903146, rs7901695, rs12255372, rs11196205; of which rs7903146 and rs12255372 are the most investigated [6] [17] [31]. These variants are in strong linkage disequilibrium (LD), which allowed the identification of specific TCF7L2 haplotypes based on LD pattern [6] [17] [32].

Helgason et al. [17] reported that a TCF7L2 haplotype, characterized by the presence of the rs7903146 T allele, is associated with decreased BMI in subjects with type 2 diabetes. These findings are not in agreement with our results.

In this study, we replicated the association of two TCF7L2 SNPs with T2DM in the Argentinean population. In our hands, significant association of minor alleles of rs7903146 ( $\mathrm{p}=0.029$; OR $=2.58)$ and rs12255372 ( $\mathrm{p}=$ 0.05 ; OR $=2.29$ ) with T2DM was found. Thus our results reiterate TCF7L2 as the most promising T2DM susceptible gene that has been most universally replicated. While the risk allele of each of the two TCF7L2 SNPs was highly significantly associated with T2DM, the greatest risk of developing the disease was conferred by rs7903146, which is consistent with the findings from other studies, such as white Europeans, West Africans, Mexicans, African Americans, Indians, and Japanese [6] [33] [34], with the exception of the study on Pima Indian populations, in which contradictory results have been reported [31].

Further, the risk conferred by homozygotes is much higher than the heterozygote carriers and it is marked in case of rs7903146. Thus our study not only shows consistency with the earlier findings in case of the association of risk alleles but also conforms to the pattern of multiplicative model of inheritance hypothesized by Grant $e t$ al. [6] in which the risk conferred by homozygotes was higher than that of the heterozygotes for the two SNPs.

Despite TCF7L2 being the most promising T2DM susceptible gene, the precise mechanism of action of TCF7L2 SNPs in the etiology of T2DM is still unclear as all the SNPs of TCF7L2 identified so far are found in the intronic regions. It is necessary to understand how these intronic SNPs affect the expression of TCF7L2. Interestingly, none of the variants found in the exonic regions were associated with the T2DM. The underlying mechanism by which intronic variations of the TCF7L2 gene without obvious function in gene regulation contribute to the development of type 2 diabetes in most populations remains to be elucidated. One possibility is that the association with type 2 diabetes reflects linkage disequilibrium with more distant functional alleles.

In the other hand, a recent study has shown that the rs7903146 polymorphism modifies an enhancer element [35]. The stronger effects seen for rs7903146 when compared with rs12255372 in T2DM supports the hypothesis that rs7903146 is a strong candidate for the functional variant.

Future studies are needed for unveiling additional variants in TCF7L2 gene, and their precise role in the regulation of beta cell mass and function, and in determining long-term disease progression.

This is the first study that examined the association of two variants of TCF7L2 gene in Argentinean population. Consistent with the functional relevance of this gene, the results from our investigation are well in line with numerous other studies consistently showing that TCF7L2 variants rs7903146 and rs12255372 are associated with T2DM and influence the risk of diabetes via pancreatic beta cell dysfunction [27] [36].

Given that the population of this region was not genetically explored hitherto for any of the complex genetic disorders, T2DM in particular, it is necessary to assess the role of different candidate genes in the etiology of T2DM in Juana Koslay and other regions of Argentina with high prevalence of T2DM, to gauge the heterogeneity in the susceptible genetic profile of the Argentinean population, in general, which is characterized by enormous geographic, ethnic and genetic heterogeneity.

We consider that our study contributes to this end significantly, even if it appears to only reiterate the oft observed strong association of the TCF7L2 SNPs with the risk of developing T2DM in the diverse populations of the world, reiterating universality of its association across ethnic groups. Further, our study could have also 
helped in understanding the effect of ethnicity, if existent, on the T2DM susceptible genes.

\section{Conclusion}

In conclusion, our results add to the rapidly expanding body of evidence that implicates $T C F 7 L 2$ as an important risk factor for type 2 diabetes in multiple ethnic groups. Our research suggests that the TCF7L2 polymorphisms can be a good clinical biomarker to predict the risk of Type 2 Diabetes Mellitus. Because TCF7L2 may affect the patient's ability to control glucose levels in serum, therefore the risk of developing diabetes could be reduced by strict glycemic control and making intensive lifestyle changes (specifically nutrition and exercise counseling).

\section{Conflict of Interests}

The authors declare no conflict of interests with respect to the present paper.

\section{Acknowledgements}

This research was supported by grants from the Universidad Nacional de San Luis (MSO-9900). We are grateful to Dr. Roberto Lucero for recruiting the study subjects and coordinating data collection.

\section{References}

[1] American Diabetes Association (2003) Screening for Type 2 Diabetes. Diabetes Care, 26, S21-S24. http://dx.doi.org/10.2337/diacare.26.2007.S21

[2] Shaw, J.E., Sicree, R.A. and Zimmet, P.Z. (2010) Global Estimates of the Prevalence of Diabetes for 2010 and 2030. Diabetes Research and Clinical Practice, 87, 4-14. http://dx.doi.org/10.1016/j.diabres.2009.10.007

[3] Poulsen, P., Kyvik, K.O., Vaag, A. and Beck-Nielsen, H. (1999) Heritability of Type II (Non-Insulin-Dependent) Diabetes Mellitus and Abnormal Glucose Tolerance-A Population-Based Twin Study. Diabetologia, 42, 139-145. http://dx.doi.org/10.1007/s001250051131

[4] Florez, J.C., Hirschhorn, J. and Altshuler, D. (2003) The Inherited Basis of Diabetes Mellitus: Implications for the Genetic Analysis of Complex Traits. Annual Review of Genomics and Human Genetics, 4, 257-291. http://dx.doi.org/10.1146/annurev.genom.4.070802.110436

[5] Permutt, M.A., Wasson, J. and Cox, N. (2005) Genetic Epidemiology of Diabetes. The Journal of Clinical Investigation, 115, 1431-1439. http://dx.doi.org/10.1172/JCI24758

[6] Grant, S.F., Thorleifsson, G., Reynisdottir, I., Benediktsson, R., Manolescu, A., Sainz, J., Helgason, A., Stefansson, H., Emilsson, V., Helgadottir, A., et al. (2006) Variant of Transcription Factor 7-Like 2 (TCF7L2) Gene Confers Risk of Type 2 Diabetes. Nature Genetics, 38, 320-323. http://dx.doi.org/10.1038/ng1732

[7] Scott, L.J., Mohlke, K.L., Bonnycastle, L.L., Willer, C.J., Li, Y., Duren, W.L., Erdos, M.R., Stringham, H.M., Chines, P.S., Jackson, A.U., et al. (2007) A Genome-Wide Association Study of Type 2 Diabetes in Finns Detects Multiple Susceptibility Variants. Science, 316, 1341-1345. http://dx.doi.org/10.1126/science.1142382

[8] Saxena, R., Voight, B.F., Lyssenko, V., Burtt, N.P., de Bakker, P.I., Chen, H., Roix, J.J., Kathiresan, S., Hirschhorn, J.N., Daly, M.J., et al. (2007) Genome-Wide Association Analysis Identifies Loci for Type 2 Diabetes and Triglyceride Levels. Science, 316, 1331-1336. http://dx.doi.org/10.1126/science.1142358

[9] Zeggini, E., Weedon, M.N., Lindgren, C.M., Frayling, T.M., Elliott, K.S., Lango, H., Timpson, N.J., Perry, J.R., Rayner, N.W., Freathy, R.M., et al. (2007) Replication of Genome-Wide Association Signals in UK Samples Reveals Risk Loci for Type 2 Diabetes. Science, 316, 1336-1341. http://dx.doi.org/10.1126/science.1142364

[10] Zhang, C., Qi, L., Hunter, D.J., Meigs, J.B., Manson, J.E., van Dam, R.M. and Hu, F.B. (2006) Variant of Transcription Factor 7-Like 2 (TCF7L2) Gene and the Risk of Type 2 Diabetes in Large Cohorts of U.S. Women and Men. Diabetes, 55, 2645-2648. http://dx.doi.org/10.2337/db06-0643

[11] van Vliet-Ostaptchouk, J.V., Shiri-Sverdlov, R., Zhernakova, A., Strengman, E., van Haeften, T.W., Hofker, M.H. and Wijmenga, C. (2007) Association of Variants of Transcription Factor 7-Like 2 (TCF7L2) with Susceptibility to Type 2 Diabetes in the Dutch Breda Cohort. Diabetologia, 50, 59-62. http://dx.doi.org/10.1007/s00125-006-0477-z

[12] Scott, L.J., Bonnycastle, L.L., Willer, C.J., Sprau, A.G., Jackson, A.U., Narisu, N., Duren, W.L., Chines, P.S., Stringham, H.M., Erdos, M.R., et al. (2006) Association of Transcription Factor 7-Like 2 (TCF7L2) Variants with Type 2 Diabetes in a Finnish Sample. Diabetes, 55, 2649-2653. http://dx.doi.org/10.2337/db06-0341

[13] Saxena, R., Gianniny, L., Burtt, N.P., Lyssenko, V., Giuducci, C., Sjogren, M., Florez, J.C., Almgren, P., Isomaa, B., 
Orho-Melander, M., et al. (2006) Common Single Nucleotide Polymorphisms in TCF7L2 Are Reproducibly Associated with Type 2 Diabetes and Reduce the Insulin Response to Glucose in Nondiabetic Individuals. Diabetes, 55, 2890-2895. http://dx.doi.org/10.2337/db06-0381

[14] Mayans, S., Lackovic, K., Lindgren, P., Ruikka, K., Agren, A., Eliasson, M. and Holmberg, D. (2007) TCF7L2 Polymorphisms Are Associated with Type 2 Diabetes in Northern Sweden. European Journal of Human Genetics, 15, 342346. http://dx.doi.org/10.1038/sj.ejhg.5201773

[15] Marzi, C., Huth, C., Kolz, M., Grallert, H., Meisinger, C., Wichmann, H.E., Rathmann, W., Herder, C. and Illig, T. (2007) Variants of the Transcription Factor 7-Like 2 Gene (TCF7L2) Are Strongly Associated with Type 2 Diabetes but Not with the Metabolic Syndrome in the MONICA/KORA Surveys. Hormone and Metabolic Research, 39, 46-52. http://dx.doi.org/10.1055/s-2007-957345

[16] Humphries, S.E., Gable, D., Cooper, J.A., Ireland, H., Stephens, J.W., Hurel, S.J., Li, K.W., Palmen, J., Miller, M.A. and Cappuccio, F.P. (2006) Common Variants in the TCF7L2 Gene and Predisposition to Type 2 Diabetes in UK European Whites, Indian Asians and Afro-Caribbean Men and Women. Journal of Molecular Medicine, 84, 1-10. http://dx.doi.org/10.1007/s00109-006-0108-7

[17] Helgason, A., Palsson, S., Thorleifsson, G., Grant, S.F., Emilsson, V., Gunnarsdottir, S., Adeyemo, A., Chen, Y., Chen, G., Reynisdottir, I., Benediktsson, R., et al. (2007) Refining the Impact of TCF7L2 Gene Variants on Type 2 Diabetes and Adaptive Evolution. Nature Genetics, 39, 218-225. http://dx.doi.org/10.1038/ng1960

[18] Groves, C.J., Zeggini, E., Minton, J., Frayling, T.M., Weedon, M.N., Rayner, N.W., Hitman, G.A., Walker, M., Wiltshire, S., Hattersley, A.T., et al. (2006) Association Analysis of 6736 UK Subjects Provides Replication and Confirms TCF7L2 as a Type 2 Diabetes Susceptibility Gene with a Substantial Effect on Individual Risk. Diabetes, 55, 26402644. http://dx.doi.org/10.2337/db06-0355

[19] Damcott, C.M., Pollin, T.I., Reinhart, L.J., Ott, S.H., Shen, H., Silver, K.D., Mitchell, B.D. and Shuldiner, A.R. (2006) Polymorphisms in the Transcription Factor 7-Like 2 (TCF7L2) Gene Are Associated with Type 2 Diabetes in the Amish: Replication and Evidence for a Role in both Insulin Secretion and Insulin Resistance. Diabetes, 55, $2654-2659$. http://dx.doi.org/10.2337/db06-0338

[20] Chandak, G.R., Janipalli, C.S., Bhaskar, S., Kulkarni, S.R., Mohankrishna, P., Hattersley, A.T., Frayling, T.M. and Yajnik, C.S. (2007) Common Variants in the TCF7L2 Gene Are Strongly Associated with Type 2 Diabetes Mellitus in the Indian Population. Diabetologia, 50, 63-67. http://dx.doi.org/10.1007/s00125-006-0502-2

[21] Zhang, W., Duan, S., Bleibel, W.K., Wisel, S.A., Huang, R.S., Wu, X., He, L., Clark, T.A., Chen, T.X., Schweitzer, A.C., et al. (2008) Identification of Common Genetic Variants That Account for Transcript Isoform Variation between Human Populations. Human Genetics, 125, 81-93. http://dx.doi.org/10.1007/s00439-008-0601-x

[22] Graham, R.R., Kozyrev, S.V., Baechler, E.C., Reddy, M.V., Plenge, R.M., Bauer, J.W., Ortmann, W.A., Koeuth, T., González Escribano, M.F., Pons-Estel, B., et al. (2006) A Common Haplotype of Interferon Regulatory Factor 5 (IRF5) Regulates Splicing and Expression and Is Associated with Increased Risk of Systemic Lupus Erythematosus. Nature Genetics, 38, 550-555. http://dx.doi.org/10.1038/ng1782

[23] Lyssenko, V., Lupi, R., Marchetti, P., Del Guerra, S., Orho-Melander, M., Almgren, P., Sjögren, M., Ling, C., Eriksson, K.F., Lethagen, A.L., et al. (2007) Mechanisms by Which Common Variants in the TCF7L2 Gene Increase Risk of Type 2 Diabetes. Journal of Clinical Investigation, 117, 2155-2163. http://dx.doi.org/10.1172/JCI30706

[24] Ahlzén, M., Johansson, L.E., Cervin, C., Tornqvist, H., Groop, L. and Ridderstråle, M. (2008) Expression of the Transcription Factor 7-Like 2 Gene (TCF7L2) in Human Adipocytes Is Down Regulated by Insulin. Biochemical and Biophysical Research Communications, 370, 49-52. http://dx.doi.org/10.1016/j.bbrc.2008.03.006

[25] The Expert Committee of the Diagnosis and Classification of Diabetes Mellitus (1997) Report of the Expert Committee on the Diagnosis and Classification of Diabetes Mellitus. Diabetes Care, 20, 1183-1197. http://dx.doi.org/10.2337/diacare.20.7.1183

[26] Friedewald, W.T., Levy, R.I. and Fredrickson, D.S. (1972) Estimation of the Concentration of Low-Density Lipoprotein Cholesterol in Plasma, without Use of the Preparative Ultracentrifuge. Clinical Chemistry, 18, 499-502.

[27] Ye, S., Dhillon, S., Ke, X., Collins, A.R. and Day, I.N. (2001) An Efficient Procedure for Genotyping Single Nucleotide Polymorphisms. Nucleic Acids Research, 29, E88. http://dx.doi.org/10.1093/nar/29.17.e88

[28] Jin, T. (2008) The WNT Signalling Pathway and Diabetes Mellitus. Diabetologia, 51, 1771-1780. http://dx.doi.org/10.1007/s00125-008-1084-y

[29] Yi, F., Brubaker, P.L. and Jin, T. (2005) TCF-4 Mediates Cell Type-Specific Regulation of Proglucagon Gene Expression by Beta-Catenin and Glycogen Synthase Kinase-3beta. The Journal of Biological Chemistry, 280, 1457-1464. http://dx.doi.org/10.1074/jbc.M411487200

[30] Smith, U. (2007) TCF7L2 and Type 2 Diabetes-We WNT to Know. Diabetologia, 50, 5-7. http://dx.doi.org/10.1007/s00125-006-0521-z 
[31] Guo, T., Hanson, R.L., Traurig, M., Muller, Y.L., Ma, L., Mack, J., Kobes, S., Knowler, W.C., Bogardus, C. and Baier, L.J. (2007) TCF7L2 Is Not a Major Susceptibility Gene for Type 2 Diabetes in Pima Indians: Analysis of 3,501 Individuals. Diabetes, 56, 3082-3088. http://dx.doi.org/10.2337/db07-0621

[32] Bodhini, D., Radha, V., Dhar, M., Narayani, N. and Mohan, V. (2007) The rs12255372(G/T) and rs7903146(C/T) Polymorphisms of the TCF7L2 Gene Are Associated with Type 2 Diabetes Mellitus in Asian Indians. Metabolism, 56, 1174-1178. http://dx.doi.org/10.1016/j.metabol.2007.04.012

[33] Cauchi, S., El Achhab, Y., Choquet, H., Dina, C., Krempler, F., Weitgasser, R., Nejjari, C., Patsch, W., Chikri, M., Meyre, D., et al. (2007) TCF7L2 Is Reproducibly Associated with Type 2 Diabetes in Various Ethnic Groups: A Global Meta-Analysis. Journal of Molecular Medicine, 85, 777-782. http://dx.doi.org/10.1007/s00109-007-0203-4

[34] Lukacs, K., Hosszufalusi, N., Dinya, E., Bakacs, M., Madacsy, L. and Panczel, P. (2012) The Type 2 Diabetes-Associated Variant in TCF7L2 Is Associated with Latent Autoimmune Diabetes in Adult Europeans and the Gene Effect Is Modified by Obesity: A Meta-Analysis and an Individual Study. Diabetologia, 55, 689-693. http://dx.doi.org/10.1007/s00125-011-2378-z

[35] Gaulton, K.J., Nammo, T., Pasquali, L., Simon, J.M., Giresi, P.G., Fogarty, M.P., Panhuis, T.M., Mieczkowski, P., Secchi, A., Bosco, D., et al. (2010) A Map of Open Chromatin in Human Pancreatic Islets. Nature Genetics, 42, 255259. http://dx.doi.org/10.1038/ng.530

[36] Loos, R.J., Franks, P.W., Francis, R.W., Barroso, I., Gribble, F.M., Savage, D.B., Ong, K.K., O’Rahilly, S. and Wareham, N.J. (2007) TCF7L2 Polymorphisms Modulate Proinsulin Levels and Beta-Cell Function in a British Europid Population. Diabetes, 56, 1943-1947. http://dx.doi.org/10.2337/db07-0055 